\title{
Laicidade do Estado e da educação Valorizando as discussões sobre gêneros e sexualidades nas escolas públicas
}

\author{
Laicism in the State and in Education \\ Valuing discussions on gender and sexuality in public schools
}

\section{Secularidad del Estado y de la Educación}

Valorando las discusiones sobre género y sexualidad en las escuelas públicas

DENIZE SEPULVEDA*

Universidade do Estado do Rio de Janeiro, São Gonçalo, RJ, Brasil.

JOSÉ ANTONIO SEPULVEDA*

Universidade Federal Fluminense, Niterói, RJ, Brasil.

\begin{abstract}
RESUMO: O objetivo deste artigo é apresentar possibilidades de ações que potencializam o debate sobre gêneros e sexualidades nas escolas públicas brasileiras, tendo em vista o movimento conservador que estamos vivendo. Concluímos que uma importante arma contra o preconceito nas escolas é a defesa da laicidade do Estado e da educação.

Palavras-chave: Laicidade. Gêneros. Sexualidade. Escolas públicas.
\end{abstract}

\begin{abstract}
The purpose of this article is to introduce possibilities of actions - which strengthens the debate on gender and sexuality inside Brazilian public schools - in view of the conservative moment that we
\end{abstract}

* Mestra em Educação pela Universidade Federal Fluminense e Doutora em Educação pela Universidade do Estado do Rio de Janeiro. Atualmente é Professora da Universidade do Estado do Rio de Janeiro, Coordenadora do Grupo de Pesquisa Gênero, Sexualidades e Diversidades nos Vários EspaçosTempos Cotidianos (GESDI) e Sub-líder do Grupo de Estudos e Pesquisa Conservadorismo e a Educação Brasileira (GEPCEB). E-mail:<denizesepulveda@hotmail.com>.

** Mestre e Doutor em Educação pela Universidade Federal do Rio de Janeiro. Atua como Professor na Universidade Federal Fluminense. É líder do Grupo de Estudos e Pesquisa Conservadorismo e Educação Brasileira (GEPCEB) e Sub-líder do Grupo de Estudo e Pesquisa Gêneros, Sexualidades e Diferenças nos Vários EspaçosTempos da História e dos Cotidianos (GESDI). E-mail: <jamsepulveda3@hotmail.com>. 
are living in. We conclude that an important weapon against prejudice in schools is the defense of laicism in the state and in education.

Keywords: Secularity. Gender. Sexuality. Public schools.

RESUMEN: El objetivo de este artículo es presentar posibilidades de acciones que potencien el debate sobre género y sexualidades en las escuelas públicas brasileñas, frente al movimiento conservador que estamos viviendo. Concluimos que defender la secularidad del Estado y la educación es un arma importante contra los prejuicios en las escuelas.

Palabras clave: Secularidad. Géneros. Sexualidad. Escuelas públicas.

\section{Introdução}

partir de pesquisas ${ }^{1}$ pudemos verificar que no cotidiano de algumas esco-
las existem discriminações e perseguições em relações axs ${ }^{2}$ alunxs LGBTIS+ ${ }^{3}$
(lésbicas, gays, bissexuais, travestis, transexuais, transgêneros, intersexuais e simpatizantes); tais procedimentos são praticados muitas vezes por algunxs professorxs e por funcionárixs. A partir de um conjunto de entrevistas, essxs professorxs e funcionárixs atribuíram a causa da homossexualidade dessxs alunxs a duas questões básicas: doença ou por uma orientação educacional errada. Elxs alegavam em suas narrativas que a homossexualidade é condenada pela Bíblia e que, por serem educadorxs, possuíam a missão de curar e educar xs alunxs homossexuais para que elxs voltassem para o caminho correto, que é o caminho religioso.

Sendo assim, verificamos que a questão da discriminação para com xs alunxs lésbicas, gays, bissexuais, travestis, transexuais e transgêneros em algumas escolas estava motivada pelas questões religiosas de algunxs professorxs e funcionárixs. Tais valores e crenças religiosas muitas vezes possibilitam que práticas lesbofóbicas, gayfóbicas, bifóbicas, transfóbicas e machistas se instalem nos cotidianos de muitas escolas públicas.

A lesbofobia (ou lesbifobia) abarca múltiplas formas de reação conservadora em relação às mulheres lésbicas como pessoas, como um casal ou como um grupo social. Com apoio nas categorias de sexo ou gênero biológico, orientação sexual, identidade lésbica e expressão de gênero, a reação conservadora engloba manifestações de preconceito, discriminação e abuso. A lesbofobia é um sexismo contra as mulheres e está relacionado com a gayfobia e vice-versa. Cynthia Petersen apud Sepulveda \& Sepulveda (2019 b), professora de Direito na Universidade de Ottawa, definiu lesbofobia como "o medo que as mulheres têm de amar outras mulheres, assim como o medo que os homens (incluindo gays) têm das mulheres não amá-los". 
Assim, a lesbofobia apresenta-se como uma série de atitudes conservadoras e sentimentos negativos (aversão, desprezo, ódio ou medo) para com as lésbicas, que vivenciam suas sexualidades fora da norma heterossexual. Esses sentimentos têm gerado práticas de discriminação e perseguição, assim como crimes, dentre os quais, homicídios. As lésbicas, assim como os gays, são vítimas de discriminação e muitas vezes tratadas por termos depreciativos. Uma das maiores discriminações de que são vítimas é a invisibilidade (SEPULVEDA, 2018a).

Gayfobia é um termo usado para designar uma forma de preconceito e aversão aos gays em geral, apresentando-se como uma série de atitudes e sentimentos negativos (aversão, desprezo, ódio ou medo) com essas pessoas.

Bifobia é um termo usado para descrever o medo, aversão ou discriminação contra a bissexualidade ou em relação às pessoas que são bissexuais. Também pode significar o ódio, a hostilidade, a desaprovação ou preconceito contra o comportamento sexual bissexual.

A transfobia se configura por atitudes de discriminação e preconceito motivados por sentimentos ou ações contra pessoas travestis, transexuais, não binárias, agêneras e outras identidades que estão na ramificação ou em direção a qualquer identidade das pessoas transgêneras e que pode ser expressa por ações, em sua maioria, hostis em relação a essas pessoas. A transfobia pode ser causada por repulsa emocional, medo, violência, raiva, desconforto e discursos de ódio, motivados pela não aceitação dessas expressões de gênero, por questões religiosas, desconhecimento, moralismo ou por alienação. A transfobia é semelhante ao racismo e ao sexismo (CAVALCANTE \& SEPULVEDA, no prelo).

Interfobia é o temor e não aceitação aos corpos que possuem variantes nas suas características sexuais. As pessoas intersexuais não podem ser classificadas na norma binário do sexo. A interfobia se alimenta do medo do diferente. Origina-se também das definições rígidas que a sociedade normativa possui sobre o que é ser homem e ser mulher. A interfobia ocorre a partir da negação do reconhecimento de que os corpos intersexuais podem viver uma vida plena e satisfatória.

As práticas machistas são comportamentos, por opiniões e atitudes, de indivíduos que recusam a igualdade de direitos e deveres entre os gêneros sexuais, favorecendo e enaltecendo o sexo masculino sobre o feminino. Portanto, o machista é o indivíduo que exerce o machismo. No pensamento machista existe um sistema hierárquico de gêneros, onde o masculino está sempre em posição superior ao feminino. Ou seja, o machismo é a ideia errônea de que os homens são "superiores" às mulheres.

A ideologia do machismo está impregnada nas raízes culturais da sociedade burguesa ocidental há séculos, tanto no sistema econômico e político mundial, como nas religiões, na mídia e no núcleo família, este último apoiado em um regime patriarcal, onde a figura masculina representa a liderança. Nesse cenário, a mulher encontra-se num estado de submissão ao homem, perdendo o seu direito de livre expressão ou sendo forçada pela sociedade machista a servir e assistir as vontades 
do marido ou do pai, caracterizando um tradicional regime patriarcal (SEPULVEDA \& SEPULVEDA, 2019, p. 63).

O machismo está intrinsecamente ligado à cultura patriarcal de muitas sociedades. Tal cultura é desenvolvida no interior de um sistema social em que homens adultos mantêm o controle, o poder e a liderança política. Por esse motivo, possuem a autoridade moral, gozam de privilégios e têm o controle das propriedades.

Segundo Sepulveda \& Sepulveda (2016), vivenciamos o recrudescimento do discurso conservador na sociedade brasileira, o qual vem ganhando força e manifesta-se a partir da reprodução de práticas LGBTIfóbicas e machistas. Assim, torna-se importante entender mais sobre o conservadorismo.

\section{O conservadorismo}

Sepulveda e Sepulveda (2019b) defendem que o conservadorismo é uma categoria histórica, ou seja, deriva de processos sociais através do tempo. Conhecemos o conservadorismo porque frequentemente as pessoas se comportam de forma conservadora. Este processo histórico gera certa regularidade de argumentos para situações análogas, o que nos permite observar o desenvolvimento de uma cultura conservadora. Dessa forma, não é possível se pensar em conservadorismo como categoria estática, tanto sociológica quanto antropologicamente.

Assim, entendemos conservadorismo como uma retórica, uma narrativa de mundo em disputa no campo da cultura. Tal narrativa só pode ser compreendida em seu processo histórico e tem como principal característica a naturalização das desigualdades sociais. Segundo Thompson (2012), a história é marcada por disputas, em especial por aquilo que se vinculou chamar de "luta de classes". Ou seja, na disputa por poder no campo da cultura, o conservadorismo é um importante elemento na construção dos interesses de classe e na própria consciência de classe. Em tal processo, não estão em disputa somente as condições materiais de sobrevivência, estão também as condições simbólicas, compostas por diversas argumentações de diferentes naturezas.

Com efeito, é possível pensar, tendo como base Mannhein (1959) e Löwy (2000), que o conservadorismo é uma visão de mundo, ou estilo de pensamento que produz uma narrativa de sociedade. Segundo Mannheim (1959, p. 79), "o pensamento humano se desenvolve em 'estilos' e há diferentes escolas de pensamento distinguíveis pelos diferentes modos como utilizam diferentes padrões e categorias de pensamento". Há que compreender como se forma o estilo do pensamento conservador, pois herdamos a crença filosófica de que o pensamento não se desenvolve como uma parte, como uma parcela do processo histórico, mas se enraíza na sociedade como natureza de um ente 
absoluto; ou que, de acordo com xs historiadorxs literários, o pensamento humano é fruto da personalidade do indivíduo. Primeiramente, isso faz com que a história do pensamento pareça artificialmente homogênea e indiscriminada. Da mesma forma, Löwy (2000) entende que os indivíduos quando nascem são inseridos na cultura e suas experiências constroem as visões sociais de mundo.

Vale ressaltar ainda que outros autores também entendem o conservadorismo como narrativa ou retórica de mundo. Segundo Hirschmam (1992), é admissível identificar uma retórica do conservadorismo político, a qual se apresenta como enfrentamento a qualquer mudança de ordem política que se proponha, de alguma forma, a modificar as relações de poder em uma sociedade. Esse autor afirma que estudou 200 anos da retórica conservadora para identificar suas características e conseguiu categorizá-la em três teses: tese da perversidade, tese da futilidade e tese da ameaça.

De acordo com a tese da perversidade, qualquer ação proposital para melhorar um aspecto da ordem econômica, social ou política só serve para exacerbar a situação que se deseja remediar. A tese da futilidade sustenta que as tentativas de transformação social serão infrutíferas, que simplesmente não conseguirão 'deixar uma marca'. Finalmente, a tese da ameaça argumenta que o custo da reforma ou mudança proposta é alto demais, pois coloca em perigo outra preciosa realização anterior (p. 15).

Há uma crítica pertinente à obra de Hirschmam (1992) que nos afasta de sua interpretação. Esse autor reduz a retórica conservadora a três categorias que não são facilmente distinguíveis e não atendem a dinâmica rápida e fluida da cultura. Vamos tentar entender um pouco mais o conceito de cultura. Raymond Williams (2011) afirma que, nas últimas décadas do século XVIII e na primeira metade do século XIX, o conceito ganhou força e adquiriu novos significados. Ainda segundo o autor, foi a revolução industrial que impulsionou novos caminhos para a linguagem e, nisso, algumas palavras emergiram com destaque: indústria, democracia, classe, arte e cultura. Todas essas palavras e aquilo que elas representam se desenvolveram de forma interligada.

A importância dessas palavras, na nossa estrutura moderna de significados, é óbvia. As mudanças em seu uso, naquele período crítico, revelam uma mudança geral nas nossas maneiras características de pensar sobre nossa vida em comum: sobre nossas instituições sociais, políticas e econômicas; sobre os objetivos que essas instituições são destinadas a representar; e sobre as relações com essas instituições e os objetivos de nossas atividades no aprendizado, na educação e nas artes (WILLIAMS, 2011, p. 15).

A compreensão do Thompson (2012) em romper com a tradição marxista ortodoxa, que coloca em oposição a base e a superestrutura, é fundamental para o argumento que defendemos neste trabalho. Não é possível entender o conservadorismo desvinculado dos interesses de classe, mas não é só isso. O conservadorismo é reproduzido como argumento de uma retórica que ultrapassa as questões de classe, encontrando as questões 
abstratas de sobrevivência em disputa no campo da cultura, em especial nas diferentes demandas dos grupos minoritários: mulheres, lésbicas, homossexuais, negrxs, etc. Isso não quer dizer que a luta de classes desapareça. Ela simplesmente se torna mais complexa, com mais variantes.

Essas disputas se dão em todos os campos sociais e são objeto de interesse especial para o campo da educação, uma vez que as demandas dos diferentes grupos estão encontrando respaldo no campo político, exigindo uma política educacional adequada às suas conquistas.

É o caso da comunidade LGBTIs, que vem sofrendo reveses dos conservadores políticos, principalmente daqueles oriundos das bancadas religiosas dentro das assembleias legislativas do Brasil. Avanços e retrocessos ainda marcam a sua história. Nesse contexto, muitxs jovens lésbicas, gays, bissexuais, travestis, transgênerxs, transexuais, intersexuais ou aquelxs que apresentam um comportamento de gênero diferente da norma padrão vêm sofrendo maus tratos em algumas escolas. São vários os casos de lesbofobia, gayfobia, bifobia, transfofia, interfobia e machismo nas escolas brasileiras, influenciando nas tessituras identitárias de todxs xs estudantes.

As práticas impetradas às lésbicas, aos gays, axs bissexuais, às travestis, axs transgênerxs, axs transexuais, axs intersexuais, às meninas e às jovens estão fundamentadas no pensamento conservador político, fruto de um discurso hegemônico que preconiza a heterossexualidade e a gêneronormatividade como as normas metro-padrões dos comportamentos sexual e de gênero. Esse discurso está fomentando a construção do preconceito contra essas pessoas, tornando-se, assim, um instrumento poderoso de manutenção das hierarquias sociais, morais e políticas, e produzindo as hierarquizações que levam às construções das inferiorizações e dos preconceitos no cotidiano de nossas escolas, levando muitxs alunxs a viver violentos processos de exclusão escolar e social a partir de situações de subalternidade por parte de algumxs professoraxs religiosxs.

Tomando mais uma vez como referência Williams (2011), a democracia se tornou uma palavra importante para lutar contra o conservadorismo nesse universo de palavras e conceitos em disputa no mundo contemporâneo. Todavia, entendemos democracia não só como uma luta em defesa dos grupos identitários, mas sim uma luta contra as desigualdades de classe. Como bem coloca Wood (2003), a luta democrática contra as desigualdades de classe é a luta contra o próprio capitalismo.

\section{Intervenções contra prática LGBTIfóbicas e machistas}

Como consideramos importante a implementação da democracia na escola, entendemos que sua ampliação envolve o combate às práticas LGBTIfóbicas e machistas, na 
medida em que permite a todos exercer seu direito à diferença e que as pessoas possam ser o que querem ou gostariam de ser.

É necessário enfatizar que nossas pesquisas trabalham também com processos de intervenções nas escolas, não somente nas instituições por nós pesquisadas, mas em outras que, ao saber do trabalho desenvolvido, nos chamam para tecer práticas de intervenção como também aos grupos de pesquisas coordenados por nós, para desenvolver projetos que combatam tais práticas.

Nos anos de 2016, 2017, 2018 e até meados de 2019 várias foram as escolas públicas municipais ou estaduais, principalmente nos municípios de São Gonçalo, Itaboraí e Niterói, localizados no estado do Rio de Janeiro, que nos chamaram para implementar projetos de intervenção para combater práticas lesbofóbicas, gayfóbicas, bifóbicas, transfóbicas, machistas e também para palestras sobre "ideologia de gênero", pois as escolas e professorxs estão sendo acusados de ser ideólogxs de gênero. Neste momento, é importante contextualizar que estão em curso hoje no Brasil agendas conservadoras fundamentalistas de ataques aos direitos humanos e à laicidade do Estado, pondo em xeque os princípios da sociedade democrática de direitos.

O surgimento do movimento fundamentalista ocorreu na modernidade ${ }^{4}$, que é marcada pela consciência autônoma, histórica e crítica. A modernidade é contra a organização medieval, centrada na autoridade divina, ela se baseia na razão do homem e na ciência. $\mathrm{O}$ fundamentalismo religioso foi um movimento contra as novidades trazidas pela modernidade, tendo como base a narrativa sagrada a partir de um monopólio de interpretação demarcado pela religião.

A modernidade é cunhada pela dependência de toda a experiência do mundo da ciência; o fundamentalismo, em contrapartida, é caracterizado pela inimizade à ciência e à razão. Na modernidade valem formas universalistas de fundamentações morais e jurídicas; os fundamentalistas não têm escrúpulos em estender as pretensões de vigência das suas normas para além do círculo da sua confissão. $\mathrm{Na}$ modernidade as artes são autônomas; no fundamentalismo elas são conduzidas pelas rédeas de uma moral definida em termos religiosos. Na modernidade gerencia-se e administra-se conforme padrões formal-racionais; a economia e a administração política são organizadas sob a dominação fundamentalista, segundo critérios da tradição. Na modernidade as orientações religiosas são privadas; os fundamentalistas utilizam os princípios religiosos sem mediações para o dimensionamento da ordem público-política. A modernidade é caracterizada pela criação do indivíduo por si mesmo; os fundamentalistas querem reintegrar o indivíduo numa ordem estamental previamente dada pela tradição (MEYER, 1995, p. 15).

Movimentos conservadores como "Escola sem Partido" (Mesp) e as teorias conservadoras baseadas no combate à tal "ideologia de gênero" vêm promovendo uma série de ataques ao campo educacional, seja por meio de projetos de leis nas diferentes câmaras legislativas ou através do pânico moral, produzindo um imaginário que compreende o gênero como alienígena, algo que estaria fora da escola e assim deveria permanecer. 
O movimento conservador denominado Escola Sem Partido tem como uma de suas reivindicações a defesa de que x professorx é um mero instrutor e que não pode ter liberdade de ensinar suas ideias a partir de suas concepções pedagógicas, pois isso seria uma doutrinação política e ideológica, indo assim na contramão do que está presente na Carta Magna de 1988.

Art. 206. O ensino será ministrado com base nos seguintes princípios:

(...)

II - liberdade de aprender, ensinar, pesquisar e divulgar o pensamento, a arte e o saber;

III - pluralismo de ideias e de concepções pedagógicas, e coexistência de instituições públicas e privadas de ensino.

Para o conservadorismo, o papel da educação é central para a questão social, pois através dela se pode empreender uma reforma moral da sociedade, podendo permitir a internalização de uma moralidade pelos indivíduos, moralidade essa necessária para a construção da ordem social (NETTO, 2011). Sendo assim, xs conservadorxs consideram que xs professorxs têm um papel com roteiro a seguir, já que elxs são xs instrutorxs que transmitirão os valores necessários para a reforma moral da sociedade. Todavia, segundo xs adeptxs do Mesp, como xs professorxs no Brasil não estão atuando como instrutorxs da moralidade e sim como doutrinadorxs políticxs e ideológicxs, xs primeirxs passaram a perseguir xs segundxs, pois para aquelxs, xs professorxs não estão cumprindo o seu papel (SEPULVEDA \& SEPULVEDA, 2018).

Junqueira (2018) enfatiza que temos assistido nos últimos anos a uma presença forte e marcante de um ativismo religioso, que usa de um neologismo denominado "ideologia de gênero" como artefato teórico para influenciar e desenvolver novas estratégias de mobilização política e de intervenção na esfera pública. O autor cita Garbagnoli (2014) para se referir a tais estratégias como uma ofensiva reacionária, fundamentalista, de matriz católica e que ocorre em vários países.

Notadamente, nessas ofensivas engajam-se setores e grupos interessados em promover uma agenda política moralmente regressiva, especialmente (mas não apenas) orientada a conter ou anular avanços e transformações em relação a gênero, sexo e sexualidade, além de reafirmar disposições tradicionalistas, pontos doutrinais dogmáticos e princípios religiosos "não negociáveis". Na esteira dessas investidas, constroem-se discursos inflamados com vistas a produzir ou a alimentar pânico moral (Cohen, 1972, 2011), por meio de estratégias político-discursivas voltadas a arregimentar a sociedade em uma batalha em defesa da "família tradicional". Essa cruzada implica intensa mobilização política e discursiva em favor da reafirmação das hierarquias sexuais, de uma assim dita "primazia dos pais na formação moral e sexual dos filhos", da retirada da educação para a sexualidade nas escolas, da restrição ao acesso de adolescentes a informações sobre saúde sexual, do rechaço a arranjos familiares não heteronormativos, da repatologização das homossexualidades e 
transgeneridades, entre outros posicionamentos que representam cerceamentos a direitos e garantias fundamentais. Entre os objetivos dessas ofensivas adquirem centralidade os de entravar o reconhecimento dos direitos sexuais como direitos humanos (Sheill, 2008), de obstruir a adoção da perspectiva de equidade de gênero, e de fortalecer ou relegitimar visões de mundo, valores, instituições e sistemas de crenças pautados em marcos morais, religiosos, intransigentes e autoritários (JUNQUEIRA, 2018, p. 451).

O "Movimento Escola Sem Partido" alega que xs professorxs querem o fim da família nuclear, dita como tradicional, pois querem transformar meninas em meninos e meninos em meninas, por isso não querem que discussões sobre gêneros e sexualidades, continuem a ser feitas nas escolas.

Durante a campanha eleitoral para a presidência do Brasil em 2018, o candidato Jair Bolsonaro intensificou seu discurso contra o que alegava ser a "ideologia de gênero", conforme pode ser visto a seguir:

A constituição fala que família é homem e mulher. Então, se um parlamentar apresentar uma PEC dizendo que família pode ser dois homens ou duas mulheres, aceito numa boa e ponto final. Não sou contra dois homens morarem juntos e terem sua vida, mas não posso admitir isso na escola. Nosso maior patrimônio é o nosso filho e nós não vamos querer 'Joãozinho' brincando de boneca por influência da escola. Depois de certa idade, se a criança resolver ser feliz dessa forma, que seja. Não sou homofóbico, mas não quero isso (ensino de ideologia de gênero) em sala de aula e respeito a família brasileira conforme escrito em nossa constituição (ESTÁCIO, 2018, s/p5).

Nós precisamos de um presidente que trate com consideração criança em sala de aula, não admitindo ideologia de gênero, impondo a Escola Sem Partido. ${ }^{6}$

A partir da posse de Jair Bolsonaro, que faz parte do espectro político da extrema direita e é apoiado pela bancada religiosa do Congresso Nacional, os convites para desenvolver projetos de intervenção nas instituições escolares diminuíram muito. Nas duas escolas em que desenvolvíamos as pesquisas fomos chamadxs pelas direções e convidadxs a encerrar as investigações, pois havia uma ordem da Secretaria de Educação do Estado do Rio de Janeiro para não mais permitir tais temáticas de pesquisas nas escolas.

A ascensão das religiões cristãs neopentecostais, no Brasil, criou um novo concerto de forças que elegeu como inimigos as religiões de matriz africana e a secularização da sociedade, principalmente naquilo que se refere aos temas em disputa, os direitos sexuais e reprodutivos.

Segundo Blancarte (2000) e Huaco (2008), a secularização demarca a perda da influência social da religião, ou seja, há uma relativa diminuição da relação social da religião 
com um conjunto de desenvolvimentos da sociedade na qual a religião participa ou se adapta.

Contudo, a noção da secularização é complexa. Conforme diz Cunha (2016, p.57):

Secularização da cultura é mudança, portanto enseja tanto adesões quanto reações. Mudança anuncia o desconhecido, que desperta entusiasmo em alguns e receio em outros. As que mexem com a identidade de indivíduos e grupos são as que mais suscitam reações. É o caso da família.

No processo de secularização da sociedade contemporânea, a escola tornou-se um importante lócus de disputa entre religiosos e laicos. Observamos hoje que normas comportamentais do passado aparecem como "Palavra de Deus" nas práticas e nos discursos de muitxs professorxs que acreditam que lhes cabe impô-la axs alunx e estão cada vez mais comuns nas escolas públicas brasileiras (SEPULVEDA \& SEPULVEDA, 2017).

O estilo de pensamento conservador se manifesta através de discursos, efetivamente a partir de regimes de verdade (FOUCAULT, 2006). No caso dos conservadores fundamentalistas o que conta como verdade é o discurso cristão religioso. Dessa forma, um dos elementos fundamentais para xs conservadorxs fundamentalistas é a interdição (FOUCAULT, 1996) dos argumentos que fortalecem os direitos sociais e humanos das minorias, ou seja, os direitos das mulheres e da população LGBTIS+ (SEPULVEDA \& SEPULVEDA, 2019a).

Na realidade, o ponto central dos conservadorismos, ou seja, aquilo que nos faz identificar o pensamento conservador é a naturalização das desigualdades sociais, em especial a desigualdade de classes. O pensamento conservador funciona a partir da manipulação utilitarista do conceito de diferença social, pois entende que, se todxs somos diferentes, nada mais justo que a sociedade seja desigual. Dessa forma, a luta dxs conservadorxs é naturalizar todas as desigualdades existentes na sociedade e interditar todos os discursos e práticas que defendem a luta pela igualdade e a superação da sociedade de classes (SEPULVEDA \& SEPULVEDA, 2019b). Foi o que aconteceu com nossas pesquisas; elas foram interditadas por causa de valores e ações conservadoras religiosas presentes na política brasileira, que influenciaram os atos da Secretaria Estadual de Educação do Governo do Rio de Janeiro.

Contudo, muitxs professorxs tecem práticas e estratégias de enfretamento à política instituída e praticam outros currículos. Como diz Alves $\left(2017^{\circ}\right)$, a resistência se dá perante uma agenda de forças hegemônicas, que na atualidade brasileira são conservadoras, o que leva xs professorxs a criar e praticar outros currículos.

Entendemos que resistência se dá dentro de uma agenda das forças hegemônicas. Criar - próprio do ser humano - vai além da resistência, pois se dá dentro de uma agenda própria das forças dos movimentos que vão se articulando em torno de experiências mais locais. (...) Em resumo: se existem necessariamente, os movimentos 
de resistência contra o hegemônico que nos quer forçar a uma história única, existem, permanentemente, muitas outras histórias sendo vividas (ALVES, 2017, s/p9).

Dessa forma, compreendemos os currículos como criação cotidiana dxs praticantes pensantes ${ }^{10}$ das escolas e

\begin{abstract}
mais do que isso, como contribuições da escola à tessitura da emancipação social democratizante tal como defendida por Boaventura de Sousa Santos (1995; 2000; 2004; 2006; 2010). Alerto o leitor, desde já, de que o trabalho com a noção de praticantes exige compreender prática e teoria como instâncias complementares e indissociáveis do fazerpensar dos sujeitos das escolas e que se interpenetram permanentemente, não devendo ser percebidas como elementos dissociáveis de uma realidade ou reflexão qualquer (OLIVEIRA, 2012, p. 6).
\end{abstract}

Na criação cotidiana de outros currículos, algumxs professorxs de escolas públicas procuraram o Observatório da Laicidade na Educação (OLÉ), um projeto de extensão da Faculdade de Educação da Universidade Federal Fluminense, para traçar táticas e estratégias a fim de discutir sobre as questões de gênero e sexualidade nas suas instituições escolares. Elxs compreenderam que a laicidade é um dos mais importantes componentes da sociedade democrática, que defende a dignidade humana e as diferenças das minorias de gênero e sexualidade na sociedade brasileira.

Assim, o OLÉ, para atender a um maior número de educadores, em novembro de 2019 organizou o "I Fórum - Escola, Laicidade e Democracia”. Entre as várias atividades desenvolvidas pelo mencionado fórum, ressaltamos a roda de conversa "A escola discutindo religião e laicidade: relatos de experiência", composta por várixs professorxs da educação básica.

A roda de conversa foi considerada pelos participantes do fórum como um dos pontos altos do evento, pois xs professorxs puderam relatar situações de preconceito, discriminação e perseguição que vêm sofrendo em suas atuações nas escolas, como também expuseram práticas democráticas de valorização e reconhecimento das diferenças. Como exemplos, citamos: a perseguição de alguns pais fundamentalistas cristãos a professorxs que, ao cumprir a lei 10.63911, são acusados de exaltar o "diabo"; a interdição de políticos que tentam proibir práticas pedagógicas que valorizam as culturas afro-brasileiras; ações preconceituosas oriundas de professorxs, adeptxs das religiões neopentecostais ${ }^{12} \mathrm{em}$ escolas públicas contra estudantes lésbicas, gays, bissexuais, transexuais, transgênerxs, travestis e intersexuais; práticas democráticas de professorxs cristãxs, que respeitam as diferenças culturais, de gênero e sexualidade e, também, como a falta de discussão sobre a laicidade interfere na formação profissional docente. Motivados por esses relatos, outros participantes do fórum também deram depoimento. Foram duas horas e meia de intenso debate sobre a defesa e a importância da laicidade da escola pública para o fortalecimento da democracia brasileira. 


\section{Considerações finais}

No contexto de disputa de interesse pelo controle da escola pública no Brasil, a retórica religiosa, como já foi mencionada acima, é extremamente importante. Todavia, o Estado moderno se constituiu a partir de um processo de laicização, ou seja, em um movimento de afastamento das posições religiosas, o qual define que a religião não poderia dominar a esfera pública, caracterizando as diferenças entre o que era público, defendido pelo Estado laico, e o que era privado. Nesse contexto, as religiões passaram a ser entendidas como um direito individual, não cabendo, dessa forma, ao Estado criar nenhum tipo de relação com nenhuma religião a fim de respeitar as diferentes manifestações da população.

A laicização do Estado foi proclamada para retirar o monopólio da verdade das religiões no processo de construção moderna da sociedade democrática. A laicidade é um princípio da construção da democracia. Cabe a nós, que defendemos a democracia, exigir ou exercer uma ação mais efetiva na defesa da laicidade. É muito claro no mundo de hoje, principalmente no Brasil, a força que as religiões estão ganhando no campo político. A retórica conservadora alinhada com o fundamentalismo religioso está causando um estrago no debate democrático.

Todavia, a laicidade ultimamente vem sendo usada como retórica de argumentação dxs conservadorxs. O movimento Escola sem Partido tem afirmado que o princípio da laicidade está sendo ameaçado (a tese da ameaça do Hirschman), uma vez que a escola vem sofrendo um processo de ideologização esquerdista. Professorxs vêm ensinando, segundo elxs, suas visões particulares de mundo, de forma praticamente religiosa. E como agentes públicos não poderiam fazer proselitismo de nenhuma forma em instituições públicas de ensino, ferindo assim o artigo 33 da LDBEN, referente ao ensino religioso, que veda todas as formas de proselitismo religioso dxs professrxs. Se xs professorxs não podem ensinar as religiões em que acreditam, elxs também não poderiam ensinar sua visão política esquerdista. Segundo xs conservadorxs, a esquerdização, assim como a já mencionada ideologia de gênero, fere o princípio da laicidade do Estado.

Não se pode negar a eficiência de tal discurso, apesar de extremamente incoerente. Afinal, proibir práticas de aulas com debates políticos não impede a existência do debate político. Assim como a laicidade não impede a presença da religião na escola. Nem é isso que preconiza a defesa da escola laica. A laicidade não é ateísmo ou agnosticismo. É o reconhecimento de que o espaço público da escola pública não é lugar para se defender nenhuma religião, assim como não é o local para que se faça nenhuma doutrinação política. Todavia, a política e a religião são conteúdos que devem ser debatidos na escola, inclusive de forma transdisciplinar, científica e crítica.

Para finalizar, o debate sobre a laicidade deve estar presente na escola e na sociedade. Os professorxs estão, cada vez mais, procurando entender o problema da religião 
na escola e buscando saídas para isso. O I Fórum do Observatório da Laicidade na Educação foi uma demonstração do interesse desses profissionais. Vale ainda ressaltar que a laicidade também é um instrumento de luta contra o discurso conservador que tanto aflige certos grupos sociais. Esse é o caso da comunidade LGBTIS+ que vem percebendo a importância da laicidade para a defesa de suas pautas políticas

Recebido em: 02/06/2020 e Aprovado em: 15/06/2020

\section{Notas}

1 As pesquisas a que nos referimos são: "A lesbofobia e a homofobia nos cotidianos das escolas: a religião interferindo nas práticas de professoras e professores"; "Parcerias com os sujeitos praticantes das escolas: um projeto de intervenção às práticas lesbofóbicas e homofóbicas que contribuam para o desenvolvimento da emancipação social"; "Práticas preconceituosas e discriminátórias desenvolvidas no cotidiano de um colégio estadual no município de São Gonçalo"; "A implementação da democracia nos cotidianos escolares: o combate às práticas excludentes de gêneros e sexualidades"; "Emancipação social e exclusão no cotidiano escolar: a homofobia e sua influência nas tessituras identitárias".

2 O uso do " $X$ " nas palavras, do ponto de vista linguístico e gramatical, é uma forma de usar uma linguagem escrita que expresse maior igualdade entre homens e mulheres. A Língua Portuguesa determina que o plural dos substantivos deva usar o gênero no masculino. Essa generalização do plural é considerada sexista e machista por certos grupos e indivíduos, resultando assim em propostas por um gênero plural não sexista a ser adotado em Português. O uso do "X" é uma tentativa de, no âmbito da escrita, tornar a língua mais democrática. Segundo PERROT (2019, p.21) a linguagem, a gramática, contribui para o apagamento das mulheres na história, pois quando "há a mistura de gêneros, usa-se no masculino o plural: eles dissimulam elas".

3 É necessário enfatizar que acrescentamos a letra " $\mathrm{S}$ " a referida sigla por considerar que os simpatizantes e parceiros dessas identidades também vivenciam em seus cotidianos procedimentos de discriminação, preconceitos e exclusão, os quais podem ser entendidos como procedimentos diferentes; não são os mesmos, pois nenhum indivíduo sente esses processos da mesma forma, contudo sofrem essas ações. De acordo com Goffman (1988), as pessoas que compartilham da vida de indivíduos estigmatizados que sofrem processos de discriminação e preconceito são definidos como seus iguais e denominados de "informados". São sujeitos cuja situação de vida ou militância os levou a serem simpatizantes da causa e que por isso possuem aceitação do grupo; por outro lado, também sofrem da maior parte das privações, preconceitos e discriminações típicas do grupo pelo qual assumiram conviver e militar.

4 A modernidade é um período histórico específico da história do Ocidente que se iniciou em fins do século XV e estendeu-se até fins do século XVIII.

5 ESTÁCIO, Verlane. Em SE, Bolsonaro critica ideologia de gênero nas escolas. Disponível em: <https://infonet. com.br/noticias/politica/em-se-bolsonaro-critica-ideologia-de-genero-nas-escolas/>. Acesso em: 29/05/2020.

6 Disponível em: <http://www.norters.com.br/noticia/2406/economia-e-politica/eleicoes-2018:-propostas-de-jair-bolsonaro-(psl)>. Acesso em: 29/05/2020.

7 CUNHA, Luiz Antonio. O projeto reacionário de educação. Disponível em: < http://www.luizantoniocunha. pro.br/uploads/independente/ProjReacEd_livro.pdf $>$. Acesso em: 29/05/2020.

8 Disponível em: <http://www.anped.org.br/news/entrevista-com-nilda-alves-uerj-artigo-rbe-n71-formacao-de-docentes-e-curriculos-para-alem-da>. Acesso em: 28/05/2020. 
9 Disponível em: $<\mathrm{http}$ //www.anped.org.br/news/entrevista-com-nilda-alves-uerj-artigo-rbe-n71-formacao-de-docentes-e-curriculos-para-alem-da>. Acesso em: 28/05/2020.

10 A escrita das palavras junto é uma opção teórica e epistemológica das pesquisas nos/dos/com os cotidianos para enfatizar a indissociabilidade entre alguns termos tradicionalmente opostos ou diferenciados. Não se trata de um recurso estético e está embasada na argumentação de que vivemos e atuamos em redes nas quais diversos aspectos não se opõem ou anulam, ao contrário, se enredam uns aos outros tornando-os indissociáveis.

11 Lei que inclui no currículo oficial da rede de ensino a obrigatoriedade da temática História e Cultura Afro-Brasileira e dá outras providências.

12 Além de seguir as principais crenças e doutrinas do pentecostalismo tradicional (atualização dos dons do Espírito Santo, inspiração pelo Espírito Santo e "batismo de fogo", conversão e libertação do "mal demoníaco", puritanismo de conduta e distância do "mundo"), o perfil das igrejas enquadradas nesses conceitos pode ser resumido, de forma ideal-típica, como segue: exclusividade nos serviços e meios de salvação com pouca abertura interdenominacional; ênfase na realização de milagres mediatizados pelas igrejas com testemunhos públicos dos mesmos; ênfase em rituais emocionais e, sobretudo, em rituais de cura, associados a uma representação demoníaca dos males; uso intenso dos meios de comunicação de massa: impressos, radiofônicos, televisivos e informatizados; combinação de religião com marketing, dinheiro e, em alguns casos, política; sensibilidade para captar os desejos dos fieis oriundos não somente das baixas camadas sociais; projeto de constante expansão, em alguns casos para além das fronteiras nacionais (ORO, 2001, p. 73).

\section{Referências}

BLANCARTE, R. Laycidad y valores en un Estado democrático. Secretaria do Governo e O Colégio do México, 2000.

BRASIL. Constituição da República Federativa do Brasil de 1988. Presidência da República, 1988.

CAVALCANTE, Penélope \& SEPULVEDA, Denize. A trajetória educacional de mulheres trans privadas de liberdade. DANTAS, João. Caleidoscópio Travesti. UFS, no prelo.

CUNHA, Luiz Antonio. O projeto reacionário de educação. 2016. Disponível em: < http://www. luizantoniocunha.pro.br/uploads/independente/ProjReacEd_livro.pdf>. Acesso em: 29/05/2020.

ESTÁCIO, Verlane. Em SE, Bolsonaro critica ideologia de gênero nas escolas. Disponível em: $<$ https://infonet.com.br/noticias/politica/em-se-bolsonaro-critica-ideologia-de-genero-nasescolas/>. Acesso em: 29/05/2020.

FOUCAULT, Michel. A ordem do discurso. São Paulo: Loyola, 1996.

Ditos e escritos: estratégia - poder e saber. Rio de Janeiro: Forense, 2006. vol. 4.

GINZBURG, Carlo. Mitos, Emblemas e Sinais. São Paulo: Companhia das Letras, 1989.

GOFFMAN, Erving. Estigma: notas sobre a manipulação da identidade deteriorada. Rio de Janeiro: LTC, 1988.

HIRSCHMAN, Alberto. A Retórica da intransigência: perversidade, futilidade, ameaça. São Paulo: Companhia das Letras, 1992.

HUACO, M. A laicidade como princípio constitucional do Estado de Direito. In: LOREA, R. A. Em

Defesa das Liberdades Laicas. Porto Alegre: Livraria do Advogado Editora, 2008. 
JUNQUEIRA, Rogério Diniz. A invenção da "ideologia de gênero": a emergência de um cenário políticodiscursivo e a elaboração de uma retórica reacionária antigênero. Psicologia Política. vol. 18. n⿳ำ 43. pp. 449-502 set. - dez, 2018.

LÖWY, Michael. As aventuras de Karl Marx contra o Barão de Munchhausen: Marxismo e positivismo na sociologia do conhecimento. São Paulo: Cortez, 2000.

LÖWY, M; SAYRE, R. Revolta e melancolia. São Paulo: Boitempo, 2015.

MANNHEIM, Karl. O pensamento conservador. Texto Original: MANNHEIM, Karl. Essays on Sociology and Social Psychology (cap. II: "Conservative Thought"). Routledge and Kegan Paul Ltd.: Londres, 1959, pp. 74-119. Tradução de Sylvia Lyra.

MEYER, Thomas. Fundamentalismo, rebelião contra a modernidade (1989). Apud DUBIEL, Helmut. O fundamentalismo da modernidade. In: BONI, Luiz A. de (org.) Fundamentalismo. Porto Alegre: EDIPUCRS, 1995.

NETTO, Leila. O conservadorismo clássico: elementos de caracterização e crítica. São Paulo: Cortez, 2011.

OLIVEIRA, Inês Barbosa de. Democracia no cotidiano da escola. Petrópolis, RJ: DP et Alii; Brasília, DF: CNPq, 2009.

O Currículo como criação cotidiana. Petrópolis, RJ: DP et Alii; Rio de Janeiro: FAPERJ, 2012.

ORO, Ari Pedro. Neopentecostalismo: dinheiro e magia. Ilha. v., 3, n.1. Florianópolis, p. 71 - 85, 2001.

PERROT, Michele. Minha história das mulheres. São Paulo: Contexto, 2019.

SEPULVEDA, Denize. A lesbofobia e a homofobia nos cotidianos das escolas: a religião interferindo nas práticas de professoras e professores. In: Relatório de Atividades do PIBIC. Universidade do Estado do Rio de Janeiro, 2018a.

\& SEPULVEDA, José Antonio. Conservadorismo, Gêneros e Sexualidades: temáticas que se entrelaçam nas pesquisas do GESDI e do GEPCEB. In: SEPULVEDA, Denize \&AMARO, Ivan. Gêneros, Sexualidades e Educação na Ordem do Dia. Curitiba: CRV, 2018.

\&__ Trabalhando questões de gêneros: criando e recriando currículos para a valorização do feminino. Periferia, Duque de Caxias, v. 11, n. 4, p. 58-80, set./dez, 2019a.

\&___ A disciplina Ensino Religioso: história, legislação e práticas. Educação, Santa Maria, v. 42, n. 1, p. 177-190, jan./abr. 2017.

SEPULVEDA, José Antonio \& SEPULVEDA, Denize. Conservadorismo e seus impactos no currículo escolar. Currículo Sem Fronteiras, Porto Alegre, v. 19, n. 3, p. 868-892, set./dez. 2019 b.

THOMPSON, E. P. As peculiaridades dos ingleses e outros ensaios. Campinas, SP: Editora da Unicamp, 2012.

WILLIAMS, R. Cultura e sociedade: de Coleridge a Orwell. Petrópolis: Vozes, 2011.

WOOD, Ellen M. Democracia contra capitalismo: a renovação do materialismo histórico. São Paulo: Boitempo, 2003. 